\title{
How the Al-Quds Bard MAT Program Changed Mathematics' Teachers in Their Classrooms
}

\author{
Nadia Jaber \\ Mathematics Supervisor, Nablus Directorate, Ministry of Education \& Higher Education
}

Jeanne Albert

Assoc. Prof. of Math Ed, Al-Quds Bard MAT Program, Al-Quds University

Abstract

In this paper, we are going to analyse the situation in math classes in Nablus Directorate depending on reports written by their supervisor. Also we are looking at AQB courses in MAT (Master of Arts in Teaching) program for math teachers and supervisors, discussing the syllabus of these courses, in particular relating to a math supervisor. We will show how the courses met the needs of this supervisor in her work with teachers. We will concentrate on the effectiveness of using Action Research as an important strategy for MAT program in developing this supervisor's educational skills. In the third part we are going show how the assignments and the emphasis in the use of qualitative research, greatly affected the supervisor. We will also compare between teachers' work in their math classrooms before and after being in workshops organized by this supervisor who is now a graduate of the MAT program. Finally, the data was collected and analysed to describe how participation in the Al-Quds Bard MAT program changed this mathematics supervisor's workshops and how it greatly affected teachers' work in their classrooms.

Keywords: How the Al-Quds Bard MAT Program Changed Mathematics' Teachers in Their Classrooms

\section{Introduction:}

Who needs math? In an article published in the New York Times (2012)

The Author Prof. Andrew Hacker writes "It is not clear that the Math we learn in the classroom has any relation to quantitative reasoning we need on the Job". He adds: "There is no evidence that being able to prove "

$\left(x^{2}+y^{2}\right)^{2}=\left(x^{2}-y^{2}\right)^{2}+(2 x y)^{2}$

Leads for more credible political opinion or social analysis". He concludes

"making Mathematics mandatory prevent us from discovering and developing young talent. In the interest of maintaining rigor, we are depleting our pool of brainpower.". Most students agree with Prof. Hacker. They always ask questions like:

Why do we learn this stuff?

Do we really need it?

If this is the case, why do people like Prof. Peter Braun say: "Without Mathematics our civilization would collapse"? Regardless of the field of Study: Science, Medicine, Sociology, Law, Business.... Business students must take the GMAT. Medical Students must take the MCAT. Law Students must take the LSAT. All other students: Science, Sociology, History must take The GRE. Each of these test has a major section on Math. Do these students need Math? Or at least this kind of Math? A lawyer does not need to know how to how many diagonals in a 25 -sided convex polygon, but the thinking process that is involved is needed.

Why do students find it too difficult?

Failing Math at all levels affects retention more than any other academic factor

What is the Problem? Is it Math as a subject or the way we teach it? 
Do we have this problem in Palestine and the Arab world or is only in the "other countries"?

Why Singapore?

In 1997 Goh Chok Tong, Singapore prime minister presented his initiative to revolutionize the Education in his country, he called his initiative. "School that think leads a nation that learn". One of his main items in the initiative was" to move education from one that focuses on rote memorization to one that concentrate on promoting thinking skills".

This can be done, by changing the classroom into environment that promote Critical Thinking. In the past, all philosophers were also great Mathematicians: Plato, Aristotle, and Socrates, Confucius this is because mathematics was used for critical thinking.

What teachers usually do in their classes?

Give formulas and ask the student to memorize them. Tell the students this the only way to solve this problem. Do not wait for more than a second for a student to answer a question. Concentrate on computation. Focus on the answers not the method. Ask questions that require straight solution. Repeat question in the exam that you solved in the classroom. Give the students number of questions and tell them the test will be from these questions. Do not allow students to challenge your way of solving problems. Tell the students that math is a subject everybody hates but they HAVE to learn. In some of the classes that I usually attend some students have right answers, but because they do not start from what the teacher thinks, many times the teacher refuses to listen to these answers.

What teachers need to do?

Teachers should encourage students to be problem solvers. Encourage the students to discover formulas that they need to solve the problem, find other solutions and compare them, analyse complex problems, increase their accuracy and skills, they should encourage students to create their own problems and suggest solutions.

Teachers themselves should listen to their students, know what they are thinking, I think they can motivate their students to participate in classes, encourage students to apply what they learned to real life problems, and help them learn to think deeply in their subject delivery, classroom discussions, assignments and tests.

So, if we do not use problem solving in classroom then our students WILL NOT. It is as simple as that.

In her book "MATHEMATICAL MINDSETS" Boaler takes about the difference between math and other subjects; she says it's not the nature of math; rather, it is due to some serious and widespread misconceptions about the subject: that math is a subject of rules and procedures, that being at math means being fast at math, that math is all about certainty and right and wrong answers, and that math is all about numbers. These misconceptions are held by teachers, students, and parents, and they are part of reason that traditional, fault, and ineffective teaching have been allowed to continue $(P, 31)$.

\section{The problem:}

It started when I joined the MAT program in Al-Quds University, I used to think that I was a good math teacher and I wanted to be a supervisor in order to support math teachers with my experience, but I realized that first I need to learn more and more. Teachers usually teach students math formulas and solve problems as examples, and students do the same, even if it's a good problem, they start to ask students questions that make it easier and easier; teachers always say "there is no time to wait for students' thinking, we need to finish the curriculum". 


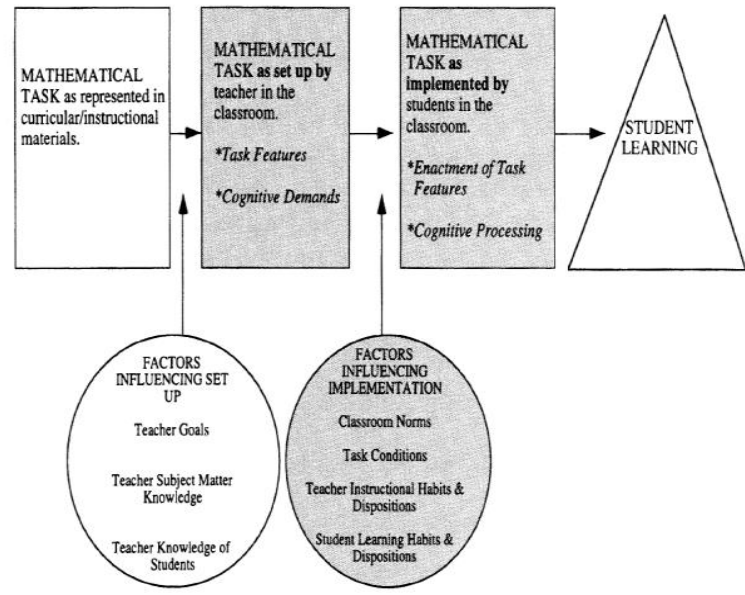

Figure 1. Relationship among various task-related variables and student learning. Shaded portions represent areas under investigation

"For example, Newman, Griffin, and Cole (1989) have provided extended ethnographic investigations surrounding the ways in which students' goal and their understanding of the objectives of the task can transform the task to the point that it is no longer the same as what was intended by the teacher at the outset. Teachers also can wittingly (or unwittingly) change the nature of tasks by stressing less- or more-challenging aspects of the tasks or by altering the resources available to students." (Stein, Grover \& Henningsen, 1996, pp. 459-460)

Many teachers don't want to change their way, simply because this is easier for them and what they are used to. Also mathematics is a very complicated topic to be learned by students and most of the time their achievement is low in it. In fact, mathematics depends on analysing and understanding deeply the concepts which will finally help the students to solve problems. All these things make teaching and learning math difficult for both students and teachers. I think we need to change the culture in math classes.

In my visits. A math teacher was not able to engage $7^{\text {th }}$ grade students in numbers class; he did all the work by himself in the class. Another teacher in $8^{\text {th }}$ grade did not offer her students the chance to think about the questions that she asks in Algebra lesson, she answered them all.

\section{What is needed for the 21 st century?}

To most people, mathematics means applying standard techniques to solve well defined problems with unique right answers. They have good reason to think that. Until the end of the 19th Century, that's exactly what it did mean! But with the rise of the modern science and technology era, the need for mathematics started to change. By and large, most people outside mathematics did not experience the change until the rapid growth of the digital age in the last twenty years. With cheap, ubiquitous computing devices that can do all of the procedural mathematics faster and more accurate than any human, no one who wants - or wants to keep - a good job can now ignore that shift from the old "application of known procedures" to new emphasis on creative problem solving.

When today's parents were going through the schools, the main focus in mathematics was on mastery of a collection of standard procedures for solving well defined problems that have unique right answers. If you did well at that, you were pretty well guaranteed a good job. Learning mathematics had been that way for several thousand years. Math textbooks were essentially recipe books. Now all those math recipes have been coded into devices, some of which we carry round in our pockets. Suddenly, in a single generation, mastery of the procedural math skills that had ruled supreme for three thousand years has become largely irrelevant. Students don't need to train themselves to do long computations, as was necessary when I was a child. No one calculates that way anymore! What they (we) need in today's world is a deeper understanding of how and why Hindu-Arabic arithmetic works. (Shapiro interviewing Devlin, 2014) 


\section{Studying at BARD}

Nearly all of Palestinian universities offer Methods of Teaching in different disciplines (math, science, English.... ) among its undergraduate and graduate programs, but they all teach subject matter classes and educational classes separately, and educational classes are for all students together. In addition, universities in Palestine depend on exams in evaluating students for educational classes. The partnership of AI-Quds/BARD Universities offers a different program! I have finished my Master's degree from Al-Quds /BARD University in the summer of 2014 in MAT program in Mathematics.

During my two years as student in Al-Quds/BARD my teachers worked hard to change my (also my colleagues') methods of teaching besides the way that we think. We acquired knowledge, skills and critical thinking from the activities and the reading which we did. In addition, our self-confidence increased from doing presentations for the articles we read.

Also I learned the process of designing a unit plan correctly, from determining the goals for the whole unit, to the assessment tools and the activities needed to explain the concepts focusing on the role of students in the learning process. Previously I had planned lesson after lesson and not the whole unit one time. Besides that, I learned how to focus and organize my work on the three major components for teaching: objectives for student learning, what I want to teach; teaching/learning activities, how to teach and what is the best method to do so; and strategies to check student understanding, the assessment of students. (CRLT, 2016)

Using games in math lessons is something great that I have never imagined before. When we began using games, I found them suitable way of teaching math especially for students who like to play games while learning and they let all students participate and take a part in the class. In BARD we needed to apply what we were learning about these games; when we learn new game in the university we needed to transform this to our classes the next day, of course we needed to make our owns with same instructions but with different questions according to the class we teach and to the curriculum, the next lecture we had to write about that difference happened in the engagement of students to classes during these games. Along two years we -as students of such program- now can develop our strategies with different games that suites our students in math classes.

The MAT program of Bard/AI Quds focuses on action research. During the two years of study teachers (students in BARD) to do have the mini-project in the $1^{\text {st }}$ year, and the CRP during the $2^{\text {nd }}$ year; in these projects they start by reading many articles about math education and start to think of the best way to change in their work in classes that would help students to be better in their participation and learning. Doing projects encouraged me to continue my work with teachers to do math by using different strategies of critical thinking, open-ended tasks, and problem-solving. In addition to that, I studied the effect of using "a new strategy" on students' achievement, and make a comparison between the new strategy and the traditional ones, and how this affects both teachers and students.

What was different for me, is that as a supervisor I needed to think about ways to change my workshops with teachers; according to Dr Jeanne" my work is with teachers whom I need to support them through different workshops, so, they can be better with their students).

During my research, I learned about several math and educational sites: http://www. nctm. org/, http://ymath. haifa. ac. il/,http://nlvm. usu. edu/en/nav/vlibrary. html, http://www. atm. org. uk/, and http://www. eric. ed. gov/.

These websites offered a lot of help for me while I was writing my papers. I read a lot about different strategies in teaching mathematics. Summarizing articles and then writing reflections about them was very helpful for me in understanding the articles deeply and enabled me to think critically about the big ideas they wrote about. Reading these articles also provided me with new strategies for motivating students' thinking and understanding. In addition, it was truly different to assess students through open-ended tasks; it is very interesting to notice the development of students' thinking about different ideas of math through tasks, games, and open-ended questions. Do we (as teachers) really need SPSS statistical program to know what is happening in our classes? I don't think so; we need to concentrate more with our students, listen to their conversations during tasks, appreciate their mistakes, and give them the opportunity to talk, because when a student talks, it is a sign that he is thinking. This gives teachers a chance to know how their students start to think and gives them time to do the game by themselves before giving it to students in order to know how it works and how to deal with it.

I also learned how to evaluate my work every time I visit teachers in their classrooms by reflecting. In addition to that, I start to ask teachers to evaluate their work after every lesson, ask themselves about their performance in the class if they 
focus on participation of all students, if they are happy or not. In fact, some teachers began to allow students to write about their feelings and what they've learned after doing an activity or a game.

I found that these courses and the action research projects I did have given me a deeper understanding of my own work as a supervisor. I became abler to describe if the lesson was successful or not according to the performance of the teacher in the class.

\section{How I changed the workshops I give for teachers?}

Learning how to do action research projects has provided me with different things that helped me to study the effects of applying new methods in teaching on teachers' and students' attitudes towards math.

As a supervisor, I was so much affected in managing my workshops with teachers; by looking for new ideas that can be linked to the students and their learning, taking care of the teachers' needs and thinking of the most suitable strategies which suites the students. In my work as a supervisor of math I'll never do workshops as I used to do, while working in my workshops with teachers I have completely changed my strategies in managing these workshops, we worked together as a team, I started to listen to their opinions (so, they will listen to their students), they can practice their thoughts and activities, they share their thoughts and experiences, they have the opportunity to choose suitable activities to do in their classes, I don't force them to use special ones. One teacher said" it was her first time that she goes back to her class with something new (which she didn't know about) and it is useful in the class". Many teachers asked me when there will be new workshops (in the same way).

In each activity I prepare for the workshops, I began to think in two things: strategy, and math concept, so, there were many new strategies (think-pair-share, games, open-questions, tasks.... ) each concerning of different concepts. By the end of the workshops each teacher has many different activities to transform to his class.

I learned how to start the class or a workshop with a short interesting activity for 3-5 minutes in order to motivate the students and prevent math anxiety. It is much better to start the lesson with a problem and to let students work than just to do some exercises. During the lesson teachers have to avoid lecturing for most of the time of the lesson. Then, they have to avoid asking questions that require memorization; they have to ask open-ended questions which have more than one answer and can be solved by different ways so as to know how they think and what they understand about math. Besides this, timing is very important in the class, as it gives students the opportunity to try to reach the solution

I used to focus on teachers' classroom discipline, but using new strategies helped teachers to have a good discipline and make learning more meaningful and interesting for all students. Still, teachers need to give the instructions for students orally not just to write them on the board. The discussion between teachers and supervisors makes big progress in the way they think and practice.

In addition, I want to work with teachers and think of how to let students be more confident, creative in their thinking and active, but the beginning will start from changing our teaching.

\section{How my work changed my teachers?}

During my visits to teachers many of them said that they will always look for learning new strategies in teaching. They asked me what unit we will do next workshops. One teacher talked about the level of achievement of her students and she said "always this unit comes in the time of exams (she was talking about Measurement for $7^{\text {th }}$ grade), so the students became hard to be engaged and so their achievement in the midterm exam for this unit does not exceed $25 \%$. But after working in new strategies after being with me in 5 workshops" the girls were so much engaged and with full attention, and also their achievement in the midterm for this year was $60 \%$ " she said.

Another teacher who's supposed to be a good teacher, she was with me in 3 workshops for using critical thinking in teaching Algebra for $6^{\text {th }}$ grade students. Before the workshops she has to work so hard in the class to be sure that many of her students can understand the meaning of "variable", immediately after the workshops she teaches the unit using several strategies "turn-over game, developing patterns...), This year I visited her in $5^{\text {th }}$ grade, she was able to develop her own game for her students to teach them fractions, and the students were setting together around her; it was a small workshop, not only a math class. After the class she said she was so much affected by the workshops and began to think of ways that makes her students more involving in classes. 
All teachers that participated in the workshops were able to do activities that make the participation of their students much better in classes; they said "it took more time to prepare these activities, but surly it made classes much more active".

Other teachers now ask related questions including both closed and open-ended tasks, and they pay more attention to open-ended questions which can enhance and promote student's motivation and their understanding. Teachers' role has also changed from lecturing to facilitating for the learning process. They've now paid more attention to teaching for more understanding by giving students chances to discover through group work more than memorizing the algorithm needed for solving problems.

In my recent visit to teachers who were in my workshops, all the teachers believed in the importance of changing their ways of teaching; they were attracted to the new strategies I did in managing the workshops, and they liked these new strategies; they said this is their first time that they participate and share their thoughts with their supervisor, so, they were convinced to do this change. They started doing some activities in their classes and these were truly successful in these classes. All the teachers said were interested in using open-ended tasks in teaching several topics in the discipline (not only Algebra and Measurement).

\section{Literature Review:}

"What is mathematics, really?" this was a question for Boaler in her new book "Mathematical Mindsets". She adds that math is different because it is taught in ways that are not used by other subject teachers, it is taught as a performance subject but not by exploring or asking deep questions. $(2015$, p. 21)

Battista (2003, quoted in Maida and Maida, 2010, p. 292) also emphasizes that: "Students' construction ... is facilitated, not by 'giving' them formulas, but by encouraging students to invent, reflect on, test, and discuss enumeration strategies in a spirit of inquiry and problem solving".

Carmody in her article wrote "Teachers know that students arrive in class with a wide range of insights and abilities; they also struggle differently and exhibit different needs. One method of incorporating this diversity is the development of openended mathematical projects, which offer the opportunity for differentiation and high levels of engagement that go beyond solving a set of pre-determined problems" (2010, P. 272). She also emphasizes elements crucial for developing an openended task:

\section{Questions to Develop an Open-Ended Mathematical Project}

With all these goals and components in mind, the OMPs begin to evolve. When

considering a new project, the following questions help to provide structure:

1. What topic is essential to the curriculum?

2. What are some meaningful and real-world applications of this topic?

3. What applications are appropriate for students of this age and level of mastery?

4. How can I include mathematical computation, algebraic notation, written expression, visual representation, peer collaboration, evaluation of complexity, and opportunities for reflection and revision?

5. What choices can I offer in terms of content or product?

6. What resources do I need for the project? Am I ensuring that all students have equal opportunities for success in terms of required resources?

7. What amount of time will students need to produce quality work?

8. How can I structure a timeline that allows for creativity and rigor? 
9. Are adequate opportunities given for differentiation to accommodate

various student needs?

10. Does this project encourage a deeper understanding of mathematics than

students would otherwise have? (Carmody, 2010, p. 274)

\section{Conclusions and Recommendations}

I have worked as a supervisor of math in Nablus Directorate of Education since the year 2008. I have worked as a math teacher in Public High Schools for 13 years. As a supervisor, I was so much affected in managing my workshops with teachers; by looking for new ideas that can be linked to the students and their learning, taking care of the teachers' needs and thinking of the most suitable strategies which suites the students.

I always know that our students have many difficulties with math and always try to find solutions, some of them have succeeded and the others haven't. Now I have learned many things that are helpful for students in the classroom, as these can motivate and force them to be engaged in the lesson with fun and interest.

Using several strategies for solving problems in teaching math is very interesting and important; it really motivates students and affects teachers' performance: teachers that participated in my workshops worked hard to avoid lectures and show a big concern of their students' conceptual thinking. Now they are able to use many activities that we did in workshops.

Overall, teachers had much ability to use problem-solving activities such as open-ended tasks and questions in their classes. Students were able to ask and answer why questions, to work together and judge their thinking in different ways.

It would be very interesting to prepare workshops as a partnership between MAT program and the Ministry of Education for teachers; both sides can understand more the others' thoughts about education.

\section{References.}

[1] Boaler,J. (2015). Mathematical Mindsets. San Francisco, CA: JOSSEY-BASS.

[2] Carmody,H. G. (2010). Water Bottle Designs and Measures. Mathematics Teaching in the Middle School. Vol. 16, No. 5. pp. 272-277.

[3] Maida,P. \& Maida,M. (2006). How Does Your Doughnut Measure Up? Mathematics Teaching in the Middle School. Vol. 11, No. 5. pp. 212-219.

[4] Shapiro, J. (2014) 5 Things You Need to Know About the Future of Math. Forbes. http://www. forbes. com/sites/jordanshapiro/2014/07/24/5-things-you-need-to-know-about-the-future-of-math/\#5c7fad45572c

[5] Stein, M. K., Grover, B. W., \& Henningsen, M. A. (1996). Building student capacity for mathematical thinking and reasoning: An analysis of mathematical tasks used in reform classrooms. American Educational Research Journal,33(2), 455-488.

[6] http://www. nytimes. com/2012/07/29/opinion/sunday/is-algebra necessary. html

[7] https://www. moe. gov. sg/media/speeches/1997/020697. htm 